\title{
UMA LEI DE REFORMA UNIVERSITÁRIA E SEUS ITINERÁRIOS
}

\author{
Carlos Roberto Jamil Cury
}

PUCMinas

\section{RESUMO:}

Este texto pretende mostrar o processo legislativo pelo qual passou o projeto da reforma universitária de 1968. A descrição do caminho de chegada para o término da lei 5.540/68 foi coletada em fontes primárias e demonstra uma conformação da maioria situacionista à iniciativa do Executivo seja no conteúdo, seja na celeridade da tramitação. À oposição restou fazer proposições que abrandassem o texto e protestar contra os aspectos mais controladores da autonomia universitária.

Palavras-chave: Educação, História da Educação, Reforma Universitária.

\section{A LAW ON UNIVERSITY REFORM AND ITS ITINERARIES}

\begin{abstract}
:
This text aims to show the legislative process of the University's Reform stablished with the law n.5.540/68. The research pursued the documents of the Deputies Chamber and of the Senate. The conclusion of the research demonstrates that the majority pertaining to the party in power took the text send by the military government lying down and also accelerated the process of the legislative procedures. The opposition protested against the articles more agressive to the autonomy of the University and searched to attenuate them. Keywords: Education, History of Education, University's Reform.
\end{abstract}

\section{Introdução}

A Lei n. 5.540 de 28 de novembro de 1968 faria, em novembro de 2008, 40 anos, se estivesse em vigor e em vigência no seu todo. Mas dela não se pode negar sua importância e seu impacto.

O mundo de então, de um lado, vivia a busca explosiva pelos direitos civis expressos na chamada contracultura, no slogan é proibido proibir e na busca de maior liberdade dos sujeitos contra padrões socio-culturais dominantes. Países da Europa e os Estados Unidos foram os mais atingidos por essa dinâmica de liberdade pessoal e cultural. De outro lado, o Brasil do início dos anos 60, sem desconsiderar a busca pelos mesmos direitos civis, buscava nas reformas de base do período a implementação de direitos sociais. Entre as reformas constava também a Reforma Universitária, anseio inclusive do movimento estudantil. O regime ditatorial reprimiu uns e outros e, em ambos os casos, quando quis satisfazer uma ou outra dessas demandas o fez à luz de sua estratégia de dominação. ${ }^{1}$

Gestada no período mais duro da ditadura, hoje essa lei ainda subsiste no que restou da lei n. 4.024/61 e na lei n. 4.024/61 com a redação dada pelas leis n. 9.131/95 e n. 9.192/95. Rigorosamente falando, seu texto não está mais nem em vigor e nem em vigência dado o artigo 92 da lei n. $9.394 / 96^{2}$. A lei n. 5.540 ainda subsiste com seu art. 16 com a redação dada pela lei n. 9.192/95 e assim esse artigo que restou pode ser compreendido nos seguintes termos: 
O fato de o novo ordenamento ser constituído em parte por normas do velho não ofende em nada o seu caráter de novidade: as normas comuns ao velho e ao novo ordenamento pertencem apenas materialmente ao primeiro; formalmente, são todas normas do novo, no sentido de que elas são válidas não mais com base na norma fundamental do velho ordenamento, mas com base na norma fundamental do novo. Nesse sentido falamos de recepção, e não pura e simplesmente de permanência do velho no novo. A recepção é um ato jurídico com o qual um ordenamento acolhe e torna suas as normas de outro ordenamento, onde tais normas permanecem materialmente iguais, mas não são mais as mesmas com respeito à forma (BOBBIO, 1994, p. 177).

Com seus acertos e desacertos, dela pode-se dizer que foi uma reforma que institucionalizou o ensino superior no Brasil, sobretudo, a figura de Universidade. E por isso seu impacto é até hoje significativo.

A literatura seguinte ${ }^{3}$ é um pequeno retrato da avaliação dessa reforma que, politicamente, nasce alguns dias antes do plúmbeo Ato Institucional n. 5, conhece a redemocratização e pode se ver totalmente revogada com o projeto de lei de reforma universitária enviada ao Congresso pelo governo Luiz Inácio Lula da Silva. ${ }^{4}$

O objetivo desse texto é o de retomar alguns aspectos legais e normativos da trajetória dessa lei. Outros autores, inclusive alguns aqui citados, traduzem com documentação e análise o contexto social, político e econômico da época. ${ }^{5}$

\section{Itinerário Legal}

O quadro inicial desse caminho foi a própria Lei de Diretrizes e Bases da Educação Nacional (lei n. 4.024/61) que deixou em aberto, no seu texto, a estrutura e funcionamento das universidades.

A descrição e a análise do caminho de chegada para o "fechamento" de uma lei de reforma universitária foram trabalhadas com bastante maestria em várias produções indispensáveis para a compreensão desse itinerário. O primeiro é o de Nicolato (1986) que retrata minuciosamente tanto a documentação legal por meio de decretos, decretos-leis e leis, antes de 1968, e a participação de diferentes atores na composição da lei tais como a União Nacional dos Estudantes (UNE), o Conselho de Reitores das Universidades Brasileiras (CRUB), o Conselho Federal de Educação (CFE), os Relatórios Atcon e MEC/USAID, o Grupo de Trabalho do Decreto n. 62.937/68, as reivindicações dos acadêmicos e a tramitação no Congresso com farta documentação ${ }^{6}$. O segundo é o de Saviani (1987) que partindo da tramitação de leis de educação no Congresso Nacional, aí incluída a lei n. 5.540/68, estuda o itinerário dos projetos no legislativo buscando o significado da trajetória rápida dos mesmos articulado ao contexto de época. O terceiro é o de Cunha (1988) cujo teor organiza o campo em matéria de ensino superior inclusive nesse período com muita documentação, trajetória parlamentar, contexto e análise. O quarto trabalho é o de Fávero (1991) que traz a documentação norteadora do Grupo de Trabalho constituído pelo Decreto n. 62.937 de 2 de julho de 1968 e a analisa à luz do contexto da época.

O texto que ora se apresenta pretende recuperar alguns aspectos desses trabalhos, acrescentar outros, mostrando o caminho de permanências/mudanças em 28 anos de vigência e mais 12 de vigência parcial.

A lei n. 5.540, sancionada em 28/11/68, ao fixar normas de organização $e$ funcionamento do ensino superior e sua articulação com a escola média, continha 5 
capítulos e 59 artigos tendo sido sancionada pelo Presidente da República com vetos incidentes sobre 43 dispositivos de 16 artigos da lei. ${ }^{7}$

Sua tramitação propriamente regimental se inicia em 2 de outubro de 1968 quando o presidente militar Arthur Costa e Silva encaminhou ao Congresso Nacional o projeto de lei da Reforma Universitária, por meio da Mensagem n. 36/68. O projeto de lei levava consigo a identificação $\mathrm{PL}(\mathrm{CN})$ n. 32/68. Acompanhava tal Mensagem a exposição de motivos do Ministro da Educação Tarso Dutra, datada de 24/09/68, a qual, em muito poucas linhas, indica que o projeto gestado no Ministério da Educação (MEC) foi concebido pelo Grupo de Trabalho da Reforma Universitária, aprovado com emendas peloConselho Nacional de Educação (CFE) e pelos Ministros a que se refere o art. $5^{\circ}$ do Decreto n. 62.937 de 2 de julho de 1968. Diz esse artigo do supracitado Decreto:

Decorrido o prazo de 30 (trinta) dias, os Ministros da Educação e Cultura, Planejamento e Coordenação Geral, Fazenda e Justiça, que representam os setores integrados na reforma universitária, promoverão, em conjunto e a curto prazo a revisão dos projetos elaborados.

A mensagem presidencial com o projeto e anexos foi lida, em sessão conjunta do Congresso Nacional, em 7/10/68, presidido então pelo vice-presidente da República Pedro Aleixo. ${ }^{8}$

O PL (CN) n. 32/68, enviado ao Congresso Nacional pelo Executivo, estava dividido em 5 capítulos e continha 45 artigos. (cf. Anexo 1) Seu processo de tramitação transcorreu em 63 dias. O trabalho de Nicolato (1986) traz a reação da oposição (MDB) que, no mesmo dia contestou o regime de urgência ${ }^{9}$ determinado no envio da mensagem ao Congresso Nacional conforme o $\S 3^{\circ}$ do art. 54 da Constituição e com mais outros 6 projetos. ${ }^{10}$ Assim, lê-se, à página 309 do volume II da dissertação dessa autora, a fala de Josaphat Marinho, senador do MDB pela Bahia que, solicitando questão de ordem, assinala:

Cumpre ao Congresso, recebendo as mensagens, dar-lhes encaminhamento regular, de maneira que não permita o tumulto que se verificará se essas sete mensagens forem lidas hoje simultaneamente, ao mesmo tempo encaminhadas às Comissões e simultaneamente aberto o prazo para que em cinco dias se façam as emendas sobre elas. Isto não é legislar. Isto será apenas, dolorosamente para o Congresso, homologar o arbítrio do Poder Executivo.

E a fala do líder da minoria, deputado pelo MDB por São Paulo, Mário Covas também aí está registrada: "A ninguém de bom senso passa desapercebido que essas mensagens estão sendo encaminhadas, neste instante, desta forma, com o único objetivo: ver esses projetos aprovados por decurso de prazo".

Geraldo Freire, da bancada governista, deputado por Minas Gerais (ARENA) defende o governo argumentando que a reforma universitária é reclamada pela juventude $e$ pelos homens maduros deste país. E já sendo outubro, postergar o envio da matéria faria com que ela só fosse discutida no outro ano e com isto quem perderia seria a Nação mesmo...

Para efeito de Parecer sobre o projeto PL (CN) n. 32/68 foi designada uma Comissão Mista instalada nos dias 8 e 9/10/68, com 23 parlamentares, sendo 16 da Aliança Renovadora Nacional (ARENA) e 7 do Movimento Democrático Brasileiro (MDB), assim composta: 
Presidente: Josaphat Marinho MDB - senador - Bahia

Relator: Lauro Cruz Arena-deputado - São Paulo

Vice-presidente: Matta Machado MDB - deputado -Minas Gerais

Membros:

$\begin{array}{ll}\text { Duarte Filho } & \text { Arena - senador - RN } \\ \text { Menezes Pimentel: } & \text { Arena - senador - CE } \\ \text { Petrônio Portella } & \text { Arena - senador - PI } \\ \text { Milton Campos } & \text { Arena - senador - MG } \\ \text { Carvalho Pinto } & \text { Arena - senador - SP } \\ \text { Ney Braga } & \text { Arena - senador - PR } \\ \text { Celso Ramos } & \text { Arena - senador - SC } \\ \text { Aderbal Jurema } & \text { Arena - deputado- PE } \\ \text { Moury Fernandes } & \text { Arena - deputado -PE } \\ \text { Wanderley Dantas } & \text { Arena - deputado -AC } \\ \text { Plínio Salgado } & \text { Arena - deputado- SP } \\ \text { Rubem Nogueira } & \text { Arena - deputado -BA } \\ \text { Aureliano Chaves } & \text { Arena - deputado - MG } \\ \text { Leão Sampaio } & \text { Arena - deputado -CE } \\ \text { Aurélio Vianna } & \text { MDB - senador - GB } \\ \text { Antonio Balbino } & \text { MDB - senador - BA } \\ \text { Adalberto Senna } & \text { MDB - senador - AC } \\ \text { Martins Rodrigues } & \text { MDB - deputado -CE } \\ \text { Hélio Navarro } & \text { MDB - deputado - SP } \\ \text { Márcio M. Alves } & \text { MDB - deputado -RJ }\end{array}$

O Relatório da Comissão Mista fez referência ao processo de elaboração da lei n. 4.024/61 (LDB), acolheu falas de depoentes tais como David Carneiro Jr., Zeferino Vaz, Florestan Fernandes, Anísio Teixeira, Moniz de Aragão, Agostinho Silva e José Leite Lopes. O Parecer citou a Universidade de Brasília como instituição renovada, apontou o Decreto - Lei n. 53/66, o Decreto - Lei n. 252/67 e o Decreto n. 62.937/68. Esse último constituiu o Grupo de Trabalho o qual elaborou vários projetos de reforma que foram considerados pelo Relator até porque acompanharam como anexo o envio do projeto de lei n. 32/68 ao Congresso Nacional.

No processo de discussão do projeto, acontecida entre os dias 10 e 16/10/68, os parlamentares apresentaram 133 emendas, todas elencadas no Relatório. Dessas, 23 emendas foram acolhidas pelo Relator, 68 foram rejeitadas e 42 foram subemendadas. $\mathrm{O}$ relator acrescentou mais 9 emendas de sua autoria com um total de 142 emendas.

Daí nasceu o primeiro substitutivo de 30/10/68 com 58 artigos em 5 capítulos (Cf. Anexo 2). ${ }^{11}$

O projeto, encaminhado ao Plenário do Congresso, foi assinado pelos seguintes parlamentares:

Presidente: Josaphat Marinho MDB - senador - Bahia

Relator: Lauro Cruz Arena-deputado - São Paulo

Vice-presidente: Matta Machado MDB - deputado -Minas Gerais

Membros: Flávio Brito Arena - senador - AM

Duarte Filho Arena - senador - RN

Eurico Resende Arena - senador - ES 


$\begin{array}{ll}\text { Raul Giuberti } & \text { Arena - senador - ES } \\ \text { Guido Mondin } & \text { Arena - senador - RS } \\ \text { Melo Braga } & \text { MDB - senador - PR } \\ \text { Adalberto Senna } & \text { MDB - senador - AC } \\ \text { Clodomir Millet } & \text { Arena - deputado - MA } \\ \text { Israel Pinheiro Fo. } & \text { Arena - deputado- MG } \\ \text { Leão Sampaio } & \text { Arena - deputado - CE } \\ \text { Martins Rodrigues } & \text { MDB - deputado - CE }\end{array}$
$5 / 11 / 68$.

O parecer 56/68 da Comissão foi lido, apresentado em 31/10/68 e publicado em

Em 6/11/68, uma 4a. Feira, às 9:00 horas da manhã, o Congresso Nacional, em sessão conjunta e em turno único, acolheu o parecer favorável da Comissão Mista do qual constavam o parecer e o substitutivo do relator deputado Lauro Cruz da Arena de São Paulo. O substitutivo continha 59 artigos em 5 capítulos.

Em discussão ${ }^{12}$, apresenta-se o deputado Último de Carvalho dizendo que o projeto não passava de um Código de Intenções e que para passar à sua efetivação dever-se-ia haver anistia para todos os estudantes grevistas das universidades públicas após o que a lei deveria prever a grevistas das universidades públicas o seu jubilamento com possibilidade de transferência para o setor privado de ensino pago. ${ }^{13}$

Josaphat Marinho, da oposição, reconhece que o projeto tem a par de normas condenáveis, disposições úteis e algumas até inovadoras. Registra a oposição à fixação como norma obrigatória e rígida que o Ensino Superior é ministrado, em princípio, através de universidades. Registra também que nõ ocorreu empate na votações da Comissão dado que a maioria governista sempre votou com o projeto do Governo.

O relator Lauro Cruz faz referência aos depoentes citados no Relatório da Comissão. ${ }^{14}$ As discussões havidas na sessão versaram sobre os dispositivos sobre o plano de trabalho das universidades durante o ano letivo, a autonomia, o espírito desconfiado do projeto face a estudantes e professores, conflito de gerações, abolição dos vestibulares, remuneração do corpo docente e estabelecimentos isolados como instituições de exceção face à regra de universidades. Também se discutiu sobre a presença em órgãos colegiados apenas das classes produtoras. Esse dispositivo foi expressamente rejeitado pela oposição mas, segundo Josaphat Marinho houve repulsa formal, completa e obstinada dos representantes da maioria.

Ao proceder o encaminhamento da votação, Mata Machado se pronuncia para que simplesmente se elimine do texto do art. $2^{o}$ a expressão excepcionalmente. E continua apresentando as razões pelas quais a Minoria aprova o substitutivo embora opondo-lhe restrições que ficaram evidenciadas.

A partir daí são votados os requerimentos de destaque, em número de 14, tendo sido aprovado apenas 1 da autoria do deputado Geraldo Freire e todos os demais sendo rejeitados.

De acordo com o conjunto da sessão e do encaminhamento da mesma, Pedro Aleixo, ao chamar a atenção da votação dos destaques, a aprovação de somente 1 e a rejeição dos demais, toma o Regimento e lê o seguinte dispositivo: Aprovado o substitutivo integral, ficam prejudicadas as emendas oferecidas ao projeto.

E, em seguida, põe em votação o substitutivo da seguinte maneira: 
Os srs. Deputados que aprovam o Substitutivo, com a ressalva do destaque, queiram conservar-se sentados. (Pausa)

Está aprovado o substitutivo na Câmara dos Deputados.

Os srs. senadores que aprovam o Substitutivo, com a ressalva do destaque, queiram conservar-se sentados. (Pausa)

Está aprovado, no Senado, o Substitutivo. (Cf. Anexo 4)

Ao final da leitura do substitutivo é votado e aprovado o destaque do deputado Geraldo Freire e Pedro Aleixo proclama: o projeto vai à Comissão para a redação final. Nesse momento, o senador Josaphat Marinho pede para fazer declaração de voto no qual, em certo momento se lê:

Cabia, entretanto, ao Partido proceder com sensibilidade, de maneira a evitar o mal maior, que era o projeto do Executivo. Daí não ter pedido verificação de votação, daí não ter admitido discussão maior para rejeição dos destaques propostos pela liderança do Governo, daí não ter pedido, especialmente, verificação para o exame definitivo dos destaques que apareceram e que foram rejeitados pela maioria. Não estamos concordes, portanto, com o que se votou. Apenas, quisemos evitar o pior que era o projeto do Poder Executivo. (Muito bem !)

E a sessão é encerrada. Na sessão do mesmo dia, às $21 \mathrm{hs}$, com a presença de 15 senadores e de 73 deputados lê-se a redação final do projeto cujo teor é encaminhado à publicação oficial.

O substitutivo foi aprovado em sessão conjunta do dia 7/11/68 às 10:30 hs. (Cf. Anexo 5) e, no mesmo dia 7/11, o projeto aprovado foi encaminhado à sanção presidencial.

A lei foi sancionada em 28 de novembro de 1968 e publicada no Diário Oficial da União de 29 de novembro de 1968.

A mensagem dos vetos foi enviada ao Congresso Nacional em 28/11/68 e o teor do documento destaca que os 43 vetos foram julgados todos contrários ao interesse público $e$ alguns eivados de inconstitucionalidade. (Cf. Anexo 6) Ressalte-se, por exemplo, a razão do veto da alínea g do art. 11 que continha a expressão transformação social entendida como permissão expressa para outro regime que não o democrático...

A Comissão Mista para apreciar os vetos foi constituída, em 3.12.68, dia em que o DOU publicou o decreto relativo aos vetos, ${ }^{15}$ pelos senadores Mello Braga, Guido Mondim, Josaphat Marinho e, em 4.12.68 ela foi completada pelos deputados Aderbal Jurema, Wanderley Dantas e Mata Machado.

Os vetos, competência da Presidência da República (art. 83, III da CF/67) cujo teor deveria ser apreciado pelo Congresso Nacional (art. 31, $\S 2^{\circ}$, IV) estavam assim regulados na Constituição de 1967:

Art 62 - Nos casos do art. $46^{16}$, a Câmara na qual se concluiu a votação enviará o projeto ao Presidente da República, que, aquiescendo, o sancionará.

$\S 1^{\circ}$ - Se o Presidente da República julgar o projeto, no todo ou em parte, inconstitucional ou contrário ao interesse público, vetá-lo-á, total ou parcialmente, dentro de dez dias úteis, contados, daquele em que o receber, e comunicará dentro de quarenta e oito horas, ao Presidente do 
Senado Federal, os motivos do veto. Se a sanção for negada quando estiver finda a sessão legislativa, o Presidente da República publicará o veto. $\mathrm{O}$ veto parcial deve abranger o texto de artigo, parágrafo, inciso, item, número ou alínea.

$\S 2^{\circ}$ - Decorrido o decêndio, o silêncio do Presidente da República Importará em sanção.

Os dispositivos vetados em parte ou no todo foram mantidos pelo Decreto-Lei $\mathrm{n}$. 618 de 10.06.69 inclusive porque ainda não foram apreciados pelo Congresso Nacional. Certamente a não apreciação tem a ver pelos tempos de regime autoritário e sob o qual o Congresso contava com uma maioria conformada e obediente. Afinal, o AI5 seria a consumação do período autoritário em 13 de dezembro de 1968.

A Reforma Universitária dessa lei contém alguns pontos importantes e que foram bastante analisados pela literatura pertinente: a forma distintiva (que deveria ser) prevalente de Universidade como lócus da indissociabilidade entre ensino, pesquisa versus a excepcionalidade (que na prática não foi o que ocorreu) de estabelecimento isolado e a federação de escolas; as duas modalidades de organização jurídica: autarquia e fundação; o departamento como base da estrutura universitária; a representação da comunidade nos órgãos colegiados; os cursos de duração plena e os de curta duração; os períodos letivos convencionais e os especiais; a possibilidade de cobrança de mensalidades; a possibilidade de dirigentes desvinculados do magistério e a extinção da cátedra. ${ }^{17}$

\section{Alterações da parte do Executivo: mudanças e complementações.}

As principais complementações e alterações sobre a lei 5.540/68 advieram, em sua maioria expressiva, da parte do Executivo tendo havido muito poucas da parte do Legislativo. Já a interpretação de artigos da mesma ficou por conta do Conselho Federal de Educação (CFE).

Relativamente ao Executivo, dotado de poderes discricionários do AI5, já no dia 31 de dezembro de 1968, por meio do Decreto-Lei n. 405, este dispõe sobre o incremento de matrículas estabelecimentos de ensino superior, com base no Ato Institucional n. $5{ }^{18}$ Esse Decreto - Lei permitia o aumento de vagas e de matrículas uma vez iniciado ou realizado o vestibular sob o critério classificatório. $\mathrm{O}$ aumento de vagas, aí incluída a formação de professores para o ensino médio, propiciaria à universidade apoio financeiro do governo federal. Incidia sobre a letra e do $\S 1^{\circ}$ do art. $3^{\circ}$ do substitutivo e que fora vetada.

Em 11 de fevereiro de 1969, o Decreto-Lei n. 464, usando os poderes autoritários do AI 5, estabeleceu normas complementares à Lei n. 5.540/68. Esse Decreto-lei revogava 23 artigos da Lei n. 4.024/61 e assim, praticamente, retirava o ensino superior daquela lei. ${ }^{19}$ E ele passava a normatizar a autorização de funcionamento de estabelecimentos de ensino superior à luz do critério de mercado de trabalho e de alto padrão de ensino e de pesquisa. Igualmente, o Decreto normatizava o reconhecimento de instituições de ensino superior, instituía o ciclo básico, regulava matrícula de aluno reprovado, estabelecia o ano letivo com 180 dias e a possibilidade de defesa direta da tese de doutorado. Ele também formalizava o modo de registro de diplomas, convertia o professor catedrático em titular, impunha a homologação ministerial para os pronunciamentos do CFE, modificava 5 dispositivos da lei n. 5.540/68, determinava uma política nacional para a formação docente, obrigava a que, em 90 dias, as universidades submetessem aos Conselhos de Educação a adaptação de seus estatutos e regimentos à Lei e ao Decreto-Lei. ${ }^{20}$ 
O Decreto n. 64.086 de 11 de fevereiro de 1969 dispunha sobre o regime de trabalho do magistério federal com a institucionalização do regime de tempo integral e da dedicação exclusiva.

O Decreto - Lei n. 477 de 26 de fevereiro de 1969 definia as infrações praticadas por docentes, estudantes e funcionários de estabelecimentos públicos ou privados e respectivas punições. O decreto-lei visou, sobretudo, as greves e os denominados movimentos subversivos.

O Decreto - Lei n. 574 de 8 de maio de 1969 proibia a redução do número de matrículas considerado na primeira série de seus cursos, no ano letivo anterior.

O Decreto - Lei n. 655, de 27 de junho de 1969, estabelecia novas normas transitórias para a execução da lei n. 5.540/68 no âmbito do ensino comercial, agrícola e industrial.

O Decreto - Lei n. 749, de 8 de agosto de 1969 estabelecia outras normas transitórias para a oferta, em nível superior, de cursos destinados à formação de profissionais de disciplinas do ensino secundário.

O Decreto - Lei n. 842, de 9 de setembro de 1969, assinado agora pela Junta Militar, altera o art. 47 da lei n. 5.540/68, pelo qual a autorização para funcionamento $e$ reconhecimento da Universidade ou estabelecimento isolado de ensino superior será tornada efetiva, em qualquer caso, por decreto ao Poder Executivo Federal, após prévio parecer favorável do Conselho de Educação competente.

O Decreto-Lei n. 869 de 1969 obrigava, em todos os graus e modalidades do ensino, no currículo, a disciplina Educação Moral e Cívica (EMC) e que, no ensino superior, seria complementada sob a forma de Estudos de Problemas Brasileiros (EPB). ${ }^{21}$

O Decreto n. 68.908 de 13 de julho de 1971 dispõe sobre a realização do concurso vestibular e a respectiva classificação de candidatos. Nas instituições oficiais a data do vestibular seria indicada pelo MEC.

O Decreto-lei n. 1051 de 21 de outubro de 1969 provê o aproveitamento de estudos realizados em seminários e faculdades de teologia para cursos de licenciatura. A lei $\mathrm{n}$. 5.789 de 27 de junho de 1972 redefine o art. $6^{\circ}$ do Decreto-Lei n. 464 estabelecendo que uma nova matrícula em instituições oficiais só seria possível quando o estudante houvesse completado o curso anterior.

A lei n. 5.802 de 11 de setembro de 1972, sancionada pelo Gal. Médici, ainda que não textualmente ligado à lei n. 5.540/68, estabelece que o título de doutor em curso credenciado de pós-graduação é requisito para a livre-docência.

A lei n. 5.850 de 7 de dezembro de 1972, redefine o art. $1^{\circ}$ do Decreto-lei n. 574 em nova redação, vedando a redução de vagas iniciais, cujo preenchimento dependa de concurso vestibular.

O Decreto n. 73.079 de 5 de novembro de 1973 estabelecendo, no sistema federal, o acréscimo de $10 \%$ e $3 \%$, respectivamente, aos pontos obtidos pelos candidatos em vestibulares oriundos de cursos profissionalizantes com mais de $1.100 \mathrm{hs}$ de formação especial ou de curso de auxiliar técnico com 300 horas de formação especial.

A lei n. 6.420 de 3 de junho de 1977 altera o art. 16 da lei n. 5.540/68 ampliando o corpo eleitoral do Conselho Universitário para um Colégio Eleitoral especial e dispondo abertura para as funções de Pró-Reitores.

A lei n. 6.625 de 23 de março de 1979, sancionada pelo Gal. Figueiredo e assinada pelo Min. Eduardo Portella, acrescenta dispositivo ao art. 26 da lei n. 5.540/68 pelo qual o Direito do Menor passa a fazer parte do currículo do curso de Ciências Sociais. 
A lei n. 6.680 de 16 de agosto de 1979 dispõe sobre a representação do corpo discente nos órgãos colegiados acadêmicos com direito a voz e voto. Essa lei revoga 2 artigos da Lei n. 5.540/68 (art. 38 e 39) e o Decreto n. 477/69. ${ }^{22}$

A lei n. 6.733 de 4 de dezembro de 1979 estabelece para as fundações instituídas ou mantidas pela União a nomeação de seus dirigentes livremente escolhidos pelo Presidente da República.

A lei n. 7.177 de 19 de dezembro de 1983 reafirma o Colégio Eleitoral e a lista sêxtupla para a escolha de dirigentes.

A lei n. 9.131 de 24 de novembro de 1995, sancionada pelo pres. Fernando Henrique Cardoso e pelo Min. da Educação Paulo Renato Souza, altera disposições da lei n. 4.024/61, (re)cria do Conselho Nacional de Educação (CNE) e estabelece, em seu art. $3^{\circ}$ avaliações periódicas das instituições e cursos de nível superior.

A Lei n. 9.192 de 21 de dezembro de 1995, altera o art. 16 da lei n. 5.540/68 com exigência do título de doutor para ser Reitor e Vice-Reitor, nomeados pelo Presidente da República, escolhidos por lista tríplice por Colégio Eleitoral do qual faça parte o Conselho Universitário e o qual, em votação uni nominal, deverá observar o mínimo de setenta por cento de membros do corpo docente no total de sua composição. Permite-se uma recondução de dirigentes e revogam-se as leis n. 6.420/77 e 7.177/83.

Finalmente, a lei n. 9.394/96, nova Lei de Diretrizes e Bases da Educação Nacional (LDBEN), em seu art. 92, revoga as disposições das Leis 4.024 de 20 de dezembro de 1961, e 5.540 de 28 de novembro de 1968, não alteradas pelas Leis 9.131, de 24 de novembro de 1995, e 9.192 de 21 de dezembro de 1995. Complementando, a Lei ${ }^{\circ}$ 10.861, de 14 de Abril de 2004, lei do SINAES, revogou a alínea a do $\$ 2^{\circ}$ do art. $9^{\circ}$ da Lei $n^{\circ}$ 4.024, de 20 de dezembro de 1961, e os arts. $3^{\circ}$ e $4^{\circ}$ da Lei $n^{\circ}$ 9.131, de 24 de novembro de 1995.

O projeto de Reforma Universitária do Governo Federal, projeto n. 7.200/06 diz, em seu Art. 58: Revogam-se o Decreto-Lei no 842, de 9 de setembro de 1969, e as Leis nos 5.540, de 28 de novembro de 1968, 6.625, de 23 de março de 1979, e 9.192, de 21 de dezembro de 1995.

Durante os 28 anos de vigência da lei n. 5.540/68, a pesquisa realizada para este estudo encontrou 22 alterações ou complementações à lei de reforma universitária como iniciativa do Executivo. Foram 11 leis, 8 decretos-leis e 3 decretos. Todas as iniciativas receberam a aprovação do Congresso Nacional. Quando o Executivo se dispunha a enviar algum projeto de lei, sua aprovação era quase que imediata e sem grandes alterações como no caso da Lei n. 5.789/72, da Lei n. 6.420/77 e da Lei n. 6.625/77.

A articulação interna entre os poderes Executivo e Legislativo evidencia, seja pelas determinações contextuais de um período autoritário em que o Congresso homologava posições do Executivo enfaticamente superdimensionado, seja pela velha política de conciliação das elites, seja pela prioridade conferida à agenda econômica do modelo vigente, quem era o real legislador.

\section{A instituição de Universidades ${ }^{23}$.}

A lei n. 5.540/68 em seu art. $5^{\circ}$ dispunha: "A organização e o funcionamento das universidades serão disciplinados em estatutos e regimentos das unidades que as constituem, os quais serão submetidos à aprovação do Conselho de Educação competente".

Por sua vez, o art. 47 da mesma lei asseverava: 
A autorização ou reconhecimento de universidade ou estabelecimento isolado de ensino superior será tornado efetivo, em qualquer caso, por Decreto do Poder Executivo, após prévio parecer favorável do Conselho Federal de Educação, observado o disposto no art. 44 desta Lei. ${ }^{24}$

E o Decreto-Lei n. 842 alterou esse art. 47 para a seguinte disposição:

A autorização para funcionamento e reconhecimento de universidade ou estabelecimento isolado de ensino superior será tornado efetiva, em qualquer caso, por Decreto do Poder Executivo Federal, após prévio parecer favorável do Conselho de Educação competente.

Entre 1968 (mas após a sanção da lei n. 5.540/68) e 1996 (porém antes da sanção da lei n. 9.394/96), houve a institucionalização de 90 Universidades, sendo 51 universidades particulares (das quais 15 comunitárias), 22 estaduais, 13 federais e 4 municipais. Entre 1983 e 1996 foram instituídas 47 particulares, sendo que, dessas, entre 1988 e 1996, foram 36 particulares. O ano campeão foi o de 1994 com 10 universidades particulares.

Algumas situações merecem ser trazidas face ao inusitado das mesmas.

A lei n. 6.951 de 6 de novembro de 1981 autoriza a instituição da Fundação Universidade da Fronteira Oeste do Rio Grande do Sul. ${ }^{25}$ Também em 6 de outubro de 1988, dia da proclamação da nova Constituição, o presidente José Sarney assinou a lei n. 7.676 pela qual se autoriza o poder executivo a criar a Universidade Federal de Cruz Alta $\mathrm{RS}^{26}$. O projeto era do deputado Rubens Ardenghi do RS.

Em 21 de dezembro de 1988, o pres. Sarney sancionou a lei n. 7.703 pela qual se institui a Fundação Universidade Federal do Planalto do Araxá - MG cuja instalação ficaria na dependência de consignação orçamentária da União e, na ausência da mesma, a Universidade não se instalou.

No mesmo dia, o presidente sancionou a Lei de n. 7.708/88 autorizando o Poder Executivo a instituir a Fundação Universidade Federal de Gurupi, no Estado de Tocantins. Com os vetos em torno do financiamento público, essa Fundação não foi adiante.

A lei n. 7.767 de 1989 autoriza o poder executivo a instituir a Fundação Universidade do Vale do Jacuí, em Cachoeira do Sul - RS. Na ausência de um decreto que a viabilizasse inclusive como instituição federal, ela também não foi adiante.

\section{Alterações da parte do Legislativo: mudanças e complementações.}

As iniciativas do Legislativo vieram tanto da Câmara de Deputados quanto do Senado Federal.

As iniciativas da Câmara versaram em torno de ingresso na universidade, via histórico escolar, obtenção de novo título, impossibilidade de o Vice-Reitor suceder ao Reitor, taxas de vestibulares, reconhecimento de instituição antes da primeira diplomação, dispensa de taxa de vestibular para candidatos não classificados em exame anterior, data de início e término do ano letivo, justificativa de falta por motivo de doença ou acidente, criação de disciplina para currículo mínimo, reconhecimento de curso, personalidade jurídica das universidades, unificação curricular de cursos, indicação e escolha de dirigentes, uniformização nacional dos currículos mínimos, vestibular, mudança do art. 16, autorização de funcionamento e reconhecimento, unificação da data do vestibular, 
facultatividade ao professor que atinja 70 anos de optar entre aposentadoria ou indenização, eleição direta de dirigentes, determinação de abertura de cursos noturnos, divisão do vestibular em 2 etapas sendo a primeira devendo ser preenchida em $50 \%$ por candidatos com renda familiar até 5 mínimos, eleições diretas para dirigentes, recondução de dirigentes, registro de diplomas pelas próprias instituições.

As tentativas de alteração por parte do Legislativo foram sendo proposituras, de modo geral, fadadas ao arquivamento, na maior parte das vezes por decurso de prazo ou, em alguns casos, por retirada pelo autor. Das 36 propostas encontradas na Câmara de Deputados, no estudo a que essa pesquisa se propôs, 31 foram arquivadas, 3 foram prejudicadas e 2 retiradas por seus autores.

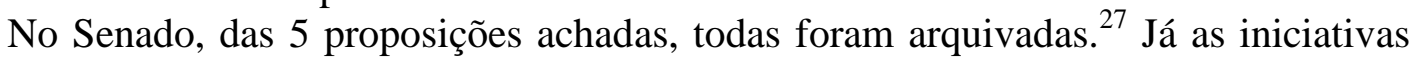
do Senado versaram sobre a alteração do art. 40 da lei, a data - limite para registro de diplomas e as transferências de alunos. ${ }^{28}$

As únicas proposições relativamente bem sucedidas como iniciativas parlamentares foram as relativas à criação de universidades que, de todo o modo, supunham a lei $\mathrm{n}$. 5.540/68 mas não sua alteração. Foram 5 iniciativas que terminaram em leis, sendo que 4 universidades não foram instituídas e implantadas e 1 só foi adiante porque teve de mudar sua personalidade jurídica de pública para privada.

\section{Alterações da parte do órgão normativo: mudanças e complementações.}

A atividade normativa da lei n. 5.540/68 se fez por meio do Conselho Federal de Educação $(\mathrm{CFE})^{29}$. Em 1961, com a promulgação da Lei n. 4.024/61 sob o regime parlamentarista, o "velho" Conselho Nacional de Educação (CNE) do Decreto n. 19.850/31 é substituído pelo Conselho Federal de Educação (CFE). Os art. $8^{\circ}$ e $\S \S$, $9^{\circ}$. da Lei n. 4.024/61 transformaram o então Conselho Nacional de Educação em Conselho Federal de Educação. ${ }^{30}$

O Conselho Federal de Educação, por sua vez, foi extinto pelos art. $4^{\circ}$. e $5^{\circ}$. da Medida Provisória n. 661/94 no governo Itamar Franco. A Lei 9.131/95, nos seus art. $5^{\circ}$. e $6^{\circ}$., confirma o teor da Medida Provisória n. 661/94 que extingue o CFE e (re)cria o Conselho Nacional de Educação. A lei n. 9.131/95, por sua vez, será referendada pelo art. $9^{\circ}$. § 1o da Lei n. 9.394/96 das Diretrizes e Bases da Educação Nacional (LDBEN).

À época, a indicação e a nomeação de Conselheiros do CFE eram da exclusiva competência do Executivo de acordo com o $\S 1^{\circ}$ do art. $8^{\circ}$ da lei 4.024/61. Ao vencer o mandato de um conselheiro ou de uma proporção dos mesmos, cabia ao presidente nomear outro ou outro grupo e assim poder recompor o Conselho com nomes julgados "confiáveis" e capazes de se compor com o Executivo e legitimar a linha dos planos governamentais. ${ }^{31}$

A Lei n. 5.540/68 atribuía várias funções ao CFE tais como: aprovar estatutos das universidades e seus respectivos regimentos (art. $5^{\circ}$ ); aprovar os regimentos dos estabelecimentos isolados (art. $6^{\circ}$ ); propor a fixação de distritos geo-educacionais (art. 10); conceituar os cursos de pós-graduação (art. 24); fixar o currículo mínimo dos cursos superiores correspondentes a profissões reguladas em lei e de outros necessários ao desenvolvimento nacional (art. 26) ${ }^{32}$; definir uma política nacional de aperfeiçoamento do pessoal docente a ser promovida pela Capes (art. 36); interpretar, na jurisdição administrativa, a lei (art. 46); suspender o funcionamento de qualquer estabelecimento isolado de ensino superior ou a autonomia de qualquer universidade, por motivo de infringência da lei (art. 48) e fixar as condições para revalidação de diplomas expedidos por estabelecimentos de ensino superior estrangeiros (art. 51). 
Esse conjunto de atribuições voltadas para o funcionamento da lei n. 5.540/68 implicou em uma plêiade de indicações, pareceres e resoluções sobre os mais diferentes assuntos. Contudo, deve-se destacar, de um lado, não só a aprovação de estatutos e regimentos das Universidades Federais como também a fixação de currículos mínimos e, de outro lado, a interpretação de artigos da lei e a conceituação da pós-graduação.

Desse modo, foi enorme o número de pareceres em vista de todos os processos que chegavam ao colegiado. Seria impossível, no âmbito desse trabalho, dar conta de volumes e volumes da revista Documenta que registra a memória de todo o período de existência do CFE, ou seja, desde 1962 até 1994 ou desse período analisado que vai de 1969 a 1994.

Mas pode-se dizer que a atuação do CFE foi fundamental para, dentro do espírito da época e dentro da conformação desejada pelo Executivo para o colegiado, dar vazão à efetivação da lei. Alguns Pareceres e Resoluções se tornaram importantes para esse colocar em ação os dispositivos legais.

\section{Conclusão}

Como conclusão pode-se verificar, de um lado, o peso de um período autoritário e discricionário no qual as liberdades são sufocadas ou restritas. Nesse momento, até pelo fato de o 31 de março ter sido um golpe de Estado dado por militares com significativo apoio da parte de segmentos civis e religiosos, o Executivo que, tradicionalmente no país já possui um poder forte e concentrado, acaba por ser, praticamente, o legislador por meio de decretos-leis ou de decretos. É o que se percebe no conjunto da tramitação da lei n. 5.540/68. As iniciativas do Executivo são rápidas e quando solicitada a aprovação delas pelo Congresso (bastante destituído pelas cassações) elas tramitam de modo célere e com todo o apoio da maioria situacionista. À oposição restava sempre o ius sperniandi, com os cuidados políticos para não tornar o controle mais pesado e mais ácido. Submisso na situação e crítico na oposição possível, o Congresso Nacional se curvou ante as exigências dos pólos de poder econômico e de poder político então vigentes. Vale aqui uma observação de Bobbio (1986) ao se referir à diferença entre um regime autoritário e um democrático. O sistema autoritário, diz ele:

[...] está em condições de controlar a demanda por ter sufocado a autonomia da sociedade civil e é efetivamente muito mais rápido na resposta por não ter que observar os complexos procedimentos decisórios próprios de um sistema parlamentar. Sinteticamente: a democracia tem a demanda fácil e a resposta difícil; a autocracia, o contrário, está em condições de tornar a demanda mais difícil e dispõe de maior facilidade para dar respostas (BOBBIO, 1986, p. 36).

E ao órgão normativo coube, docilmente, traduzir a lei em pareceres interpretativos e resoluções normativas adequadas ao pensamento hegemônico baseado tanto na Doutrina da Segurança Nacional quanto no poder do "governo dos técnicos". Voltando ao autor supracitado:

Tecnocracia e democracia são antitéticas: se o protagonista da sociedade industrial é o especialista, impossível que venha a ser o cidadão qualquer. A democracia sustenta-se sobre a hipótese de que todos podem decidir a respeito de tudo. A tecnocracia, ao contrário, pretende que sejam 
convocados para decidir apenas aqueles poucos que detêm conhecimentos específicos (BOBBIO, 1986, p. 34).

Isto não retirou a resistência silenciosa ou altaneira que as universidades públicas, após um tempo de adequação, começaram a praticar. Também não subtraiu da realidade o seu caráter contraditório pelo qual, no âmbito universitário, a recepção de um conjunto de constrangimentos legais não anulou a reinterpretação dos mesmos e nem a capacidade de crítica. Também não significou a condenação da reforma universitária como um todo por causa da manu militari que a sufragou. Muitos pontos eram já uma demanda da comunidade científica e foram introduzidos na lei como o fim da cátedra, a indissociabilidade entre ensino, pesquisa como marca da figura - universidade - e a institucionalização da pós-graduação ${ }^{33}$.

A situação pós-64 optou por um planejamento econômico de corte tecnocrático e voltado para a acumulação de capital. Isso significou que a área social tornou-se residual nas prioridades governamentais.

O movimento de contestação ao regime militar e sua derrubada contou com a ampla participação da população na qual o professorado universitário esteve sempre presente. A mobilização geral foi capaz de derrubar a ordem autoritária e de criar um novo ordenamento jurídico nacional em bases democráticas. ${ }^{34}$

A ordem jurídica de caráter democrático se impôs como um todo, aí compreendida a área educacional. Por isso, a ordem constitucional que nasceu em 1988 consagrou princípios caros à cidadania, à democracia e à educação democrática. Ela é tanto um modo de se opor ao que até então vigia em termos de medo e de despotismo, quanto uma maneira de se propor a gestação de uma nova maneira de se administrar a coisa pública ou seja sob a forma da virtude como amor pela coisa pública. Isto não significa que a construção da ordem democrática tenha se estendido do campo jurídico para o conjunto das práticas sociais e políticas. $\mathrm{O}$ autoritarismo no Brasil possui raízes mais fundas em nossa história do que o período militar, expressão recente de uma característica de nossas classes dirigentes. $^{35}$

Seja em contraposição a esta cultura instalada tradicionalmente, seja em função da criação e manutenção dos institutos próprios da democracia, nascem os princípios éticos estabelecidos em nossa Constituição de 1988, os direitos sociais, o papel ativo do Estado, os direitos civis e o direito à diferença.

Em sua autonomia, apesar dos múltiplos percalços, as universidades públicas e outras que lutam por serem dignas desse nome continuam a ser, em seus projetos institucionais, críticas de si próprias, lugar de produção de conhecimento, transmissão de conhecimentos acumulados e busca de formação de profissionais que sejam conseqüentes com a cidadania e os direitos.

\section{REFERÊNCIAS}

BRASIL. MEC/INEP. Ensino Superior: Coletânea de Legislação Básica. Rio de Janeiro: IBGE, 1969.

ANDRADE, Regis de Castro. Política Social e Normalização Institucional no Brasil. In: ANDRADE, Regis de Castro et alii. América Latina: novas estratégias de dominação. Petrópolis : Vozes, 2a . Ed, 1982. 
BOBBIO, Norberto. O futuro da democracia. Rio de Janeiro : Paz e Terra, 1986.

BOBBIO, Norberto. Teoria do Ordenamento Jurídico. Brasília: EDUNB, 1994.

CHAUÍ, Marilena. Brasil: mito fundador e sociedade autoritária. São Paulo : Perseu Abramo, 2000.

COUTINHO, Carlos Nelson. Cultura e Sociedade no Brasil: ensaios sobre idéias e formas. Rio de Janeiro : DP\&A, 2000.

CRUB. Estudos e Debates. N. 17, Brasília: 1990.

CUNHA, Luiz Antonio. A Universidade Crítica: o ensino superior na República populista. Rio de Janeiro: Francisco Alves, 1983.

CUNHA, Luiz Antônio. A Universidade Reformanda. Rio de Janeiro : Francisco Alves, 1988.

CUNHA, Luiz Antonio. Educação, Estado e Democracia no Brasil. São Paulo: Cortez; Rio de Janeiro: EDUFF, 1991.

CURY, Carlos Roberto Jamil. Conselhos de Educação: fundamentos e funções. Revista Brasileira de Política e Administração da Educação. V. 22, jan/jun 2006, p. 41-66.

CURY, Carlos Roberto Jamil. Quadragésimo Ano do Parecer CFE n. 977/65. Revista Brasileira de Educação. N. 30, set-dez 2005, p. 7-20.

FÁVERO, Maria de Lourdes de Albuquerque. Da Universidade "Modernizada" à Universidade Disciplinada: Atcon e Meira Mattos. São Paulo: Cortez; Campinas: Autores Associados, 1991.

FERNANDES, Florestan. Universidade Brasileira: reforma ou revolução. São Paulo: Alfa-Ômega, 1975.

FERREIRA, May Guimarães. O Conselho Federal de Educação: o coração da reforma. Tese de doutorado, FEUNICAMP, 1990.

FONSECA, Dirce Mendes de. Mecanismos constitutivos do poder do Conselho Federal de Educação. In: FONSECA, Dirce Mendes de. (org) O pensamento privatista em educação. Campinas: Papirus, 1992.

GERMANO, José W. Estado Militar e Educação no Brasil: 1964-1985. São Paulo: Cortez; Campinas, SP: Unicamp, 1993.

HORTA, José Silvério Bahia. Liberalismo, Tecnocracia e Planejamento Educacional no Brasil. São Paulo: Cortez e Associados, 1982.

MARTINS, Carlos Benedito. Ensino pago: um retrato sem retoques. São Paulo: Global, 1981. 
MARTINS, Carlos Benedito. O novo ensino superior privado no Brasil (1964-1980). In: Martins, Carlos Benedito (org). Ensino superior brasileiro: transformações e perspectiva. São Paulo: Editora Brasiliense. 1988.

MINTO, Lalo Watanabe. As Reformas do Ensino Superior no Brasil: o público e o privado em questão. Campinas: Associados, 2006.

NICOLATO, Maria Auxiliadora. A caminho da Lei 5.540/68 - a participação dos diferentes atores na definição da reforma universitária. Belo Horizonte: FAE/UFMG, 1986. 2 vol. (dissertação de mestrado)

OLIVEN, Arabela Campos. A paroquialização do Ensino Superior. Petrópolis, RJ: Vozes, 1990.

PAULA, Maria de Fátima de. A modernização da Universidade e a transformação da intelligentzia universitária. Florianópolis, SC: Insular, 2002.

Revista Brasileira de Ciências Sociais (RBCS). N. 23 São Paulo: ANPOCs, 1993.

RIBEIRO, Maria das Graças M. Educação Superior Brasileira: reforma e diversificação institucional. Bragança Paulista: EDUSF, 2002.

RODRIGUES, Neidson. Estado, Educação e desenvolvimento econômico. São Paulo: Cortez e Associados, 1982.

ROSSATO, Ermélio. A expansão do Ensino Superior no Brasil: do domínio público à privatização. Passo Fundo, RS: Editora Passo Fundo, 2006.

SANTOS, Oder José et alii. Expansão do Ensino Superior: características e tendências. Estudos e Debates, n. 1. Brasília: CRUB, 1978.

SAVIANI, Dermeval. Educação: do senso comum à consciência filosófica. São Paulo: Cortez; Campinas, SP: Autores Associados, 1980.

SAVIANI, Dermeval. Política e Educação no Brasil: o papel do Congresso Nacional na legislação de ensino. São Paulo: Cortez, 1987.

SAVIANI, Dermeval. Análise Crítica da Organização Escolar Brasileira através das leis Nos. 5.540/68 e 5.672/71. in GARCIA, Walter. (org) Educação Brasileira Contemporânea: organização e funcionamento. São Paulo: McGraw-Hill, 1978.

VIEIRA, Sofia Lerche. Universidade Federal nos anos 80: o jogo da política educacional. São Paulo, 1990, doutorado PUCSP.

VIEIRA, Sofia Lerche. O (dis)curso da (re)forma universitária. Fortaleza: UFC, 1982.

\footnotetext{
${ }^{1}$ A esse respeito, cf. Andrade, 1982 que trabalha certas políticas compensatórias visando hegemonia.

${ }^{2}$ Uma lei válida é a que é conforme à Constituição. Lei vigente é a que, sendo válida, segue todos os trâmites formais exercendo sua obrigatoriedade face aos fatos regulados por ela estando em plena eficácia.
} 
${ }^{3}$ Cf. Santos, 1978; Rodrigues, 1982; Vieira, 1982 e 1990; Saviani, 1987; Cunha, 1988; Martins, 1988; CRUB, 1990; Oliven, 1990; Germano, 1993; RBCS, 1993; Ridenti, 20000; Ribeiro, 2002.

${ }^{4}$ Cf. PL 7.200/06. Para uma relativa antecipação dessa Reforma, cf. Decreto n. 5.773/06.

${ }^{5}$ Cf. Fernandes, 1975; Saviani, in Garcia, 1978.

${ }^{6} \mathrm{Cf}$. Decreto - lei n. 53/66 que entre outras coisas fragmentava as Faculdades de Filosofia e criava as Faculdades ou Centros de Educação; Decreto- lei n. 252/67 que, no fundo, regulamentou e ampliou o Decreto - lei n. 53/66 e a lei n. 5.539/68.

${ }^{7}$ Os artigos são: $3^{\circ}, 9^{\circ}, 12,16,19,22,24,26,31,44,45,53,54,55,56$ e 57.

${ }^{8}$ À época o vice-presidente tinha, entre suas atribuições, a de presidir o Congresso Nacional, segundo o $\S 2^{\circ}$ do art. 79 da CF/67.

${ }^{9}$ O regime de urgência consta do Art 54 da Constituição de 1967:

o Presidente da República poderá enviar ao Congresso Nacional projetos de lei sobre qualquer matéria, os quais, se assim o solicitar, deverão ser apreciados dentro de quarenta e cinco dias, a contar do seu recebimento na Câmara cios Deputados, e de igual prazo no Senado Federal.

$\S 1^{o}$ - Esgotados esses prazos, sem deliberação, serão os projetos considerados como aprovados.

$\S 2^{\circ}$ - A apreciação das emendas do Senado Federal pela Câmara dos Deputados far-se-á no prazo de dez dias, findo o qual serão tidas como aprovadas.

$\S 3^{o}$ - Se o Presidente da República julgar urgente a medida, poderá solicitar que a apreciação do projeto se faça em quarenta dias em sessão conjunta do Congresso Nacional, na forma prevista neste artigo.

${ }^{10}$ À época, o Ato Institucional n. 2 de 1965 já extinguira os partidos tradicionais e impusera o bipartidarismo, a situação com a Aliança Renovadora Nacional (ARENA) e o Movimento Democrático Brasileiro (MDB) como oposição que não pôde ser mais combativa do que foi por causa das cassações sofridas e pelo próprio clima ditatorial.

${ }^{11}$ Para uma leitura bem detalhada das discussões e das emendas, cf. NICOLATO (1986), pgs 311-328.

${ }^{12}$ Nicolato (1986) comenta: ...o fato que logo se destaca refere-se à não verificação de um nível de debate compatível com a importância que se presume deveria ter a matéria... (col. II, p. 311)

${ }^{13}$ Cf. Lei n. 4.464/64 ou Lei Suplicy sobre órgãos de representação estudantil e que revogava o Decreto $n$.

4.105 de 1942 que reconhecia a União Nacional dos Estudantes (UNE) como representante dos estudantes. Cf. decreto n. 56.241/65 que regulamentou essa lei extinta em 1991.

${ }^{14}$ Ao que parece, segundo a referência de Lauro Cruz, tais depoentes compareceram a uma Comissão de Inquérito instaurada na Câmara dos Deputados para fazer um levantamento da situação do ensino superior no país.

${ }^{15}$ Tais vetos foram mantidos pelo Decreto-Lei n. 618 de 10/06/1969 e publicados no dia 11/06/1969. As razões dos vetos se encontram no Diário do Congresso Nacional de 01/12/1968.

${ }^{16}$ Matérias de competência da União.

${ }^{17}$ Para o conteúdo e análise da Reforma, cf. Cunha, 1988.

${ }^{18}$ Decreto-lei é um decreto com força de lei que, pelo art. 55 da Emenda Constitucional de 1969 da Junta Militar, era expedido pelo Poder Executivo.,O Congresso, de acordo com o $\S 1^{\circ}$ do mesmo artigo, deveria aprova-lo ou rejeita-lo em 60 dias. Caso não apreciado em 10 sessões, era considerado aprovado por decurso de prazo. A Constituição da República de 1988 acabou com tal dispositivo sendo que, em seu lugar, o art. 62, prevê a figura da Medida provisória.

${ }^{19}$ Foram revogados os seguintes artigos: 66 a 74,76 a 87 e 117-118.

${ }^{20}$ Com isso, a lei n. 4.024/61 ficou como apoio básico das leis n. 5.540/68 e 5.692/71, reais LDBS, respectivamente, do ensino superior e do primeiro e segundo graus.

${ }^{21}$ Já em 1967, a ADESG encaminhou ao MEC um pré-projeto de lei com a finalidade de tornar obrigatória a disciplina EMC. O MEC, por sua vez, encaminhou um projeto para o CFE e que no Congresso tomou o número de PL 770/67. Esse Decreto-Lei foi revogado pela Lei n. 8.663 de 1993 sob o governo Itamar Franco.

22 Seguindo a cronologia de normas importantes incidentes sobre o ensino superior, não se pode ignorar a Emenda Constitucional n. 24 de $1^{\circ}$. De dezembro de 1983 pela qual se recompõe a vinculação de impostos para a educação a qual havia desaparecido da CF/67. Tal emenda foi regulamentada pela Lei n. 7.388 de 24 de julho de 1985, denominada Lei Calmon e assinada pelo pres. José Sarney.

${ }^{23}$ Antes do período em análise, cumpre registrar que o mecanismo de federalização das universidades se deu com a lei n. 1.254/50. Segundo Cunha (1983) foram 39 federalizações até 1953. E até 1961 foram mais 9 instituições perfazendo 48 federalizações ao todo.

${ }^{24} \mathrm{O}$ art. 44 foi vetado.

${ }^{25}$ A lei não foi implementada. 
${ }^{26}$ Pelo Decreto n. 97.000 de 21 de outubro de 1988, institui-se a Fundação Universidade de Cruz Alta com personalidade jurídica de direito privado e suas dotações viriam dos três poderes públicos e de outras fontes privadas, inclusive de mensalidades. O governo vetou o aporte de recursos da União o que inviabilizou sua instalação nos termos desse Decreto. Essa Universidade só foi reconhecida em 1993 após o reconhecimento do CFE no Parecer CFE n. 586/93 e na Portaria Ministerial 1704/93.

${ }^{27}$ Sobre o projeto de lei do Senador Josaphat Marinho a respeito do credenciamento pelo Senado de nomes para o CFE após as indicações do Executivo. cf. Parecer CFE n. 34/70.

${ }^{28}$ O Sen. Eurico Resende, antes da Lei n. 5.540/68 solicitou ao CFE uma manifestação sobre seu projeto de Lei n. 2/68 pelo qual aquele Conselho seria desmembrado em 6 Conselhos Regionais: Fortaleza, Recife, Salvador, Belo Horizonte, Rio de Janeiro e Porto Alegre. O CFE estaria impedindo a expansão do ensino superior já que constituído por Reitores e por pessoas advindas do PSD. Cf. Parecer n. 39/68

${ }^{29}$ Cf. Decreto n. 66.296/70, art $2^{\circ}$ inciso II, letra a. Sobre Conselhos enquanto órgãos normativos, cf. Cury, 2006.

${ }^{30}$ Diz o art. 119 da Lei 4.024/61: os titulares de cargos públicos federais que forem extintos, por se tornarem desnecessários em face da presente lei, serão aproveitados em funções análogas ou correlatas. Para uma atuação analítica do CFE entre 1961 e 1968, cf. Ferreira, 1990. Para os aspectos específicos de uma reforma universitária, cf. Nicolato, 1986.

${ }^{31}$ Em 1968, o presidente Gal. Costa e Silva nomeou 5 novos membros, reconduziu 3 membros e não reconduziu nomes de personalidades como Dumerval Trigueiro, Anísio Teixeira e D. Helder Câmara. Sobre a hegemonia do setor tecnoburocrático sobre as determinações advindas do regime constitucional de 1946, cf. Horta, 1982.

${ }^{32}$ Após 1968, o CFE fixou o currículo mínimo para 56 cursos superiores, tendo mantido o currículo para 24 cursos que já possuíam tal fixação. Quanto o regime de créditos e expressão em horas de atividades, cf.

Parecer CFE n. 331/71. Por ex. Cf. Res. 3/72 (Direito); Res. 4/72 (Enfermagem e Obstetrícia), Res. 8/72 (EMC/EPB) e Parecer n. 252/69 (Pedagogia).

${ }^{33}$ Embora guiada pelo Parecer 977/65, pode-se dizer que a viabilização da pós-graduação se completou após a lei n. 5.540/68. Cf. Cury, 2005

${ }^{34}$ Cf. CUNHA, 1991.

${ }^{35}$ Cf. Chauí, 2000, Coutinho, 2000.

Artigo recebido em: 18/09/2009

Aprovado para publicação em: 30/09/2009 